\title{
MORISCOS ANDALUSÍES EN PASTRANA. LAS QUEJAS DE UNA MINORÍA MARGINADA DE MORISCOS, CON NOTICIAS SOBRE SU PARALELISMO EN EL REINO DE GRANADA
}

Aurelio García López

En particular la región de Castilla La Mancha carece de un estudio global de los moriscos. Por nuestra parte nos decidimos a realizar un breve estudio sobre la comunidad granadina instalada en Pastrana (Guadalajara) ${ }^{1}$.

No era todo poseer una amplia solvencia económica y haber creado un centro textil de los más incipientes de Castilla para que fueron considerados con las mismas condiciones de igualdad los moriscos de Pastrana que la restante población cristiana vieja de esa localidad ${ }^{2}$.

Iniciado ya el reinado de Felipe III, en los primeros años del siglo XVII, la población morisca de Pastrana estaba compuesta por unas 2.000 personas, aproximadamente un 30 por 100 del total de la población ${ }^{3}$. Era un porcentaje

* Universidad de Alcalá de Henares.

1. Sobre los moriscos de la ciudad de Guadalajara, véase: GARCía LóPEz, Aurelio: Moriscos en Tierras de Uceda y Guadalajara (1502-1610), Diputación Provincial de Guadalajara, Guadalajara, 1992.

2. Sobre la importancia económica de los moriscos de Pastrana, véanse los siguientes estudios: PRIETO BERNABE, J. M.: «Aproximación a las características antropológicas de la minoría morisca asentada en Pastrana en el último tercio del siglo XVI», en Wad-Al-Hayara, 14, 1987, pp. 355-362; id., «Los moriscos en Pastrana, según el censo de 1573», en Actas del primer Congreso de Historia de Castilla-La Mancha, Vol. VII, 1989, pp. 269-282; MARTínez MilláN, M.: «Bienes raíces de los moriscos de Pastrana», en Actas del Simposio Les morisques et leur temps, celebrado en 1981 en Montpellier (Editions du CNRS, Paris, 1983), pp. 413-430; GARCÍA LOPEZ, Aurelio: La estructura socio-económica morisca en la jurisdicción de Pastrana (1579-1610), Memoria de Licenciatura (inédita), Universidad de Alcalá de Henares, 1993.

3. LAPEYRE, Henry: Geografía de la España Morisca, Historia i societat, 14. Valencia, 1986, pp. 214. En el momento de la expulsión contabilizaban 2.214 . 
muy elevado, lo cierto es que los granadinos se habían configurado como un grupo con conciencia y mentalidad propia, pero muy desarraigado dentro de la sociedad cristiana.

Domínguez Ortiz, en 1992, ponía de manifiesto por primera vez, la posible organización y mentalidad que tuvieron los miembros de esta comunidad:

“... querríamos ahondar en la psicología de los expulsados, saber cómo reaccionaban ante la nueva situación, hasta que punto conservaron su estructura de grupo, su mentalidad, sus tradiciones, sus creencias; averiguar si fueron impermeables al entorno, a la influencia de aquella sociedad cristiana en la que vivieron inmersos durante cuarenta años, plazo insuficiente para producir un cambio radical, pero susceptible de proporcionar cambios de actitud, e incluso algunas conversiones individuales" ${ }^{\prime \prime}$.

Veamos, por nuestra parte, lo adecuada que es la cita anterior, observando la peculiaridad que tuvieron los moriscos asentados en el señorío de Pastrana.

Según los disidentes de Pastrana eran discriminados e insultados públicamente al llamarles moriscos. Pues, en 1602, el "representante de los naturales del reino de Granada" se presentaba a la reunión del concejo, indicando que no fueran llamados los miembros de la comunidad que él encabezaba: "que no los llamen moriscos y otras palabras injuriosas".

Los granadinos fueron ignorados por las autoridades municipales, y discriminados en sus propuestas. Serafín de Tapía ha señalado esta discriminación que sufrió la comunidad morisca de Avila ${ }^{5}$.

Las quejas expuestas por el representante de los naturales del Reino de Granada, en el concejo de Pastrana, dice así:

"En este ayuntamiento se hiço rrelación como a pedimento de los naturales del Reyno de Granada, sobre que no los llamen moriscos ny con otras palabras injuriosas so ciertas penas lo qual se ha pregonado públicamente en esta villa como mas largo consta de la dicha provisión, que vea el dicho ayuntamiento lo que convenga, $y$ visto por el dicho ayuntamiento; se ordeno e mandado que se suplique a su majestad sobre la dicha provision y se hagan las diligencias necesarias; y por no aver entendido otra cosa que su majestad por sus reales premgaticas los llaman de moriscos y por no diferenciar en nombre no se pueden entender quales son del dicho reyno de los cristianos viejos y por lo qual conviene que se suplique a su majestad de la dicha provisión"

4. DOMínguez OrTIZ, Antonio: «Pastrana en la coyuntura histórica del reinado de Felipe II», en La Princesa de Éboli y Pastrana, Ciclo de conferencias celebrado en Pastrana en 1992 en el IV Centenario de su muerte. Diputación Provincial de Guadalajara, 1993, p. 86.

5. TAPIA SÁNCHEZ, Serafín de: La comunidad morisca de Avila, Salamanca, 1991, pp. 282-284.

6. AMP (Archivo Municipal Pastrana), Actas del concejo, sesión 2 de marzo de 1602. 
Las autoridades municipales se desentienden del problema, responden que eran llamados así en las pragmáticas Reales, y por tanto a ellos no les corresponde solucionar este malestar de los disidentes granadinos.

Es sin duda una noticia, curiosa, que nos obliga a replantearnos el significado de la palabra "morisco" y su empleo por la historiografía actual. El uso del término "morisco" como adjetivo es anterior a su empleo para definir a un grupo social específico. Se había empleado como un adjetivo de un instrumento musical o de una característica musical, como así aparece en el poema de Alfonso XI y el en Libro del Buen Amor ${ }^{7}$. Actualmente designa al musulmán convertido al cristianismo y que fue expulsado de España, y que se estableció en el Magreb ${ }^{8}$.

Podría ser, a nuestro entender, más apropiado llamarles "andalusíes" en vez de "moriscos" que ellos consideran como un insulto. Puesto que la palabra "morisco" tiene un sentido despectivo". Aunque los andalusíes son aquellos musulmanes nacidos en España que se instalan en las ciudades del norte de Africa sin haber vivido bajo el dominio cristiano manteniendo su cultura y su lengua intactas ${ }^{10}$.

Entre la documentación emanada de la administración castellana se puede encontrar para su designación tanto la voz "moriscos" como "naturales del reino de Granada". Es un caso muy curioso que a partir del alzamiento de las Alpujarras prolifera entre las pragmáticas reales el término morisco. En las reuniones del concejo de Pastrana se empleaban ambas palabras.

Fue más la voz "moriscos" empleada como término discriminatorio por autoridades reales, municipales e inquisitoriales, que por las personas del pueblo que convivían con esta minoría marginada, es curioso, que escribanos públicos en sus escrituras notariales les llamen "naturales del reino de Granada" o los "nuevamente convertidos del Reino de Granada".

En la documentación eclesiástica se emplea la palabra "morisco". Incluso en los Sinodales del arzobispado de Toledo de 1583, en su constitución 107, aunque en su título aparece la palabra "Cristianos nuevos", pero en su texto se reitera el término "morisco", ridiculizan que se les llame como cristianos nuevos del Reino de Granada: "de los que vulgarmente se llaman cristianos nuevos, que del reyno de Granada han sido traydos a este nuestro arzobispado"11.

7. Gómez Renau, Mar: Comunidades marginadas en Valladolid. Mudéjares y moriscos, Valladolid, 1993, pp. 73-74.

8. Epalza, Míkel de: Los moriscos antes y después de la Expulsión, Madrid, 1992, p. 16.

9. Ibidem, p. 17.

10. Bunes IBARRa, Miguel Angel de: La Imagen de los musulmanes y del Norte de Africa en la España de los siglos XVI y XVII. Los caracteres de una hostilidad, C.S.I.C., Instituto de Filología, Madrid, 1989, p. 125.

11. Constituciones Sinodales hechas por Don Gaspar Quiroga, Cardenal, arzobispo de Toledo, Madrid, 1583. BN, R- 28.698, f. 65. 
La curia emplea la palabra "moro" para designar un significado de pagano. En Pastrana, en 1582, tenemos un caso clarísimo de discriminación en la utilización de la voz "moro", es detenido por Liébana ${ }^{12}$ el disidente Miguel Pérez, llamado moro verde, acusado por las muertes y robos que se habían producido en la ribera del Tajo ${ }^{13}$.

Se les puede denominar igualmente andalusíes por haber mantenido su cultura y tradiciones árabes durante su estancia en Pastrana. Era muy habitual entre los moriscos de Pastrana hablar en algarabía. En 1602, los oficiales del concejo ordenaban pregonar la pragmática en la que se prohibía hablar en algarabía a los moriscos, puesto que llegaban quejas de la población cristiana vieja sobre su empleo habitual:

"Otro si se ordeno e mando que se pregone en el placa publica de esta villa la pragmática de su majestad que habla sobre los del reino de Granada no puedan hablar algarabía y las demás cosas que en ellas se declaran que según de e cumpla como en ella se requiere so las penas en ella declaradas"14.

El concejo se limita -o pretende limitarse- a cumplir las pragmáticas reales, mediante, incluso, una fuerte presión de sus señores, los duques de Pastrana, que estaban a favor de un trato favorable hacia sus vasallos moris$\cos$, aunque en ello hubiera que quebrantar las leyes reales ${ }^{15}$.

Son varias las reuniones del concejo en que se indica que los moriscos de esta localidad hablan en algarabía. Un grupo de ellos habían sido instalado en caseríos, como era La Pangía que se encontraba a dos leguas del núcleo urbano, donde vivían de forma independiente sin tener iglesia ni control algunos por las autoridades cristianas. En Pastrana, habían levantado un barrio extramuros de la población, que denominaron Albaicín, en recuerdo al de Granada, de donde procedían la mayor parte de ellos. Circunstancias aclaratorias, en la que comprobamos que mantenían viva su lengua que practicaban comúnmente entre los miembros de esta comunidad, y en muchos casos con total libertad.

Igualmente, había mantenido esta comunidad un amplio nivel cultural, y con algunos miembros cultos; sabemos que, en 1603, contaban con su pro-

12. Sobre los asesinatos de cuadrillas de moriscos en las ciudades castellanas, véanse: JANER, F.: Condición social de los moriscos en España. Causas de su expulsión y consecuencias que esto produjo en el orden económico y político, Madrid, 1857, p. 272; VINCENT, Bernard y DOMínGUEZ ORTIZ, Antonio: Historia de los moriscos. Vida y Tragedia de una minoría, Madrid, 1984, p. 60. El doctor Liébana juez de comisión sobre el castigo de los moriscos, en 1583, recibe una prórroga de 50 días para terminar los asuntos en los que había sido encomendados, puesto que su mandato cumplía en 20 de abril de 1583 (AGS, RGS, 1583, marzo, 31).

13. APNP (Archivo Protocolos Notariales Pastrana), e.p. Sebastián Cano, 18 diciembre 1582.

14. AMP, Actas del concejo, 2 de marzo de 1602.

15. García López, Aurelio: «La Princesa de Éboli y Pastrana», en Wad-al-Hayara, 21, 1994, pp. 51-110. 
pio maestro de primeras letras que enseñaba a los niños moriscos ${ }^{16}$. De Pastrana era Muhammad Al-Wazir, que redacta para el sultán Muley Zaidán un manuscrito en castellano que se titula Apología contra la ley cristiana ${ }^{17}$. Entre los moriscos que permanecieron en Pastrana después de la expulsión, algunos de ellos que fueron procesados por la Inquisición de Toledo, declaraban saber escribir en árabe. Este es el caso entre otros, de Diego Alguacil, que, en 1613 , en el proceso que se le siguió, declaraba que conocía oraciones en árabe y las sabía traducir al castellano ${ }^{18}$.

Finalmente -y esto es lo más significativo e importante-, que gracias al descubrimiento en las casas dejadas por los moriscos al ser expulsados de unos lotes de libros escritos en árabe se puede pensar en el fuerte arraigo que tenía la cultura musulmana entre las élites moriscas de Pastrana ${ }^{19}$.

A través de la queja, en la que indican que no sean llamados moriscos, vemos su conciencia de grupo. Puesto que esta comunidad al contar con su represente propio, es que tenía derecho de poder reunirse todos ellos para darle su opinión, y ésta fuera presentada en el concejo.

Habría que recordar que los moriscos granadinos tenían prohibido reunirse desde la promulgación de la pragmática de 1572. Es importante, porque mantiene su conciencia de grupo para defenderse ante los atropellos que se cometen contra ellos.

Pero, sin duda, la comunidad de Pastrana había avanzado muchisimo en este sentido, ya desde 1594, tenían permitido reunirse para tratar sus asuntos. En ese año, los moriscos ante los numerosos pleitos que tenían por sus agravios y deudas económicas con la población cristiana vieja tuvieron que solicitar al rey, una licencia para poder reunirse y defender sus numerosos pleitos. Ante esta petición, que es aceptada por Felipe II, se informa por provisión Real a los alcaldes ordinarios de Pastrana, que entre las noticias que tenían de los moriscos de esa localidad:

16. AMP, Actas del concejo, 26 de abril 1603.

17. BN, Mss. 9074, titulado Apología contra los Artículos de la ley Cristiana. Sin fecha. Aparece el nombre del autor como Muhamad alguazir. El apellido se escribe con la misma gráfica como en la documentación de Pastrana, empleando la z en lugar de la c. Sobre este autor, véanse los siguientes trabajos: SAAVEDRA Y MORAGAS, D.: «Discurso que el Excelentisimo señor don Eduardo Saavedra leyó en Junta Pública de la Real Academia Española, el día 29 de diciembre de 1878, al tomar posesión de su plaza de Académico de número", en Memorias de la Real Academia Española, tomo VI, Madrid, 1889; CARDAillaC, L.: Morisques et chrétiens. Un affrontement polémique (1492-1640), Paris, 1977, pp. 187 y 195; WIEGERS, Gerard: "Diplomatie et polemique anti-chetienne: Naissance et influence de l'oeuvre de Muhammad Alguazir (Vers 1021/1621)", en Le Ve Centenaire de la Chute de Grenade 14921992, Tomo II, Ceromdi, 1993, pp. 747-756.

18. AHN, Inquisición, legajo 2106-13.

19. BlázQuez Miguel, Juan: La Inquisición en Castilla-La Mancha, Madrid, 1986, p. 43. 
"que heran tantas las molestias y vejaciones que cada día recibían que vos las dichas justicias y de otras muchas personas que les hacían que no podían dejar de acudir ante nos a pedir remedio de ello; para lo qual y según los pleitos e causas que sobre ellos les moviades, avia menester darles poder e curadores, letrados y otras personas que les ayudasen e para ello juntarse a dar sus poderes e por que se themian que si lo haçian los prenderiades y hariades sobre ellos muchas molestias y vejaciones, nos pidio y suplico le diésemos dar nuestra carta e provisión para que lo dicho que parte e los demás naturales del reyno de Granada se puedan juntar luego y cada quando se les ofreciere a dar el poder o poderes que sean nesçesarios a las personas que les convenga sin que sobre ello les hagáis agravio ni bejación alguna".

El consejo Real accede a esta petición, y ordena: "os mandamos que quiriendose juntar los naturales del dicho reino de Granada alistados en la dicha villa a tratar y platicar acerca de lo suso dicho, e dar poder para seguir sus pleitos e causas e pedir su justicia sobre ello los dejéis e consistais hacer por una vez estando presente vos el dicho alcalde mayor o uno de vuestros alcaldes hordinarios y no de otra manera alguna" 20 .

Contar con el privilegio de reunirse en presencia del Alcalde Mayor y poder elegir un Procurador para que defendiese sus pleitos, era una circunstancia que ya había tenido su antecedente inmediato en el denominado "Procurador" que los nuevamente convertidos del Reino de Granada poseían con anterioridad a 1568, en Granada. La comunidad morisca del reino de Granada contaba con su propio receptor y procurador, que manifiesta sus quejas al consejo Real en nombre de los nuevamente convertidos del reino de Granada ${ }^{21}$.

Las quejas por parte de los moriscos por ser discriminados cuando se presentaban ante la justicia ${ }^{22}$ fueron muy corrientes entre la población granadina repartida por el interior de Castilla. Sobre todo, en las que decían que no podían defenderse de sus pleitos. En 1592, los moriscos de Ciudad Real se quejaban al consejo Real de Castilla sobre este asunto ${ }^{23}$. Ese mismo año, Juan Fernández, morisco de Pastrana, se querella contra la sentencia del pleito que mantenía con doña Magdalena de Covarrubías ${ }^{24}$.

20. APNP, e.p. Sebastián Cano, 10 abril 1595. Se inserta el traslado de la cédula real, dado en Madrid a 19 de marzo de 1594 .

21. AGS, RGS, 1558-VIII-9. Título de Procurador de los nuevamente convertidos del reino de Granada a Jorge de Baeza.

22. Tomás y VAliente, F.: Manual de Historia del Derecho Español, Madrid, 1979, p. 176. La comunidad marginada morisca no tuvo derecho alguno, se trataba de una comunidad cultural "segregada, reducida y marginada".

23. AGS, RGS, 1592, enero 21.

24. AGS, RGS, 1592, noviembre 15 . 
Fueron quejas expuestas por los disidentes granadinos que se produjeron desde los primeros días de su repartimiento por tierras castellanas. En 1571, los moriscos del Campo de Montiel, escribían al Consejo Real de Castilla, quejándose de los malos tratos que recibían por la justicia:

"criminalmente a todos los vecinos del dicho campo que pareçieren culpados... nos hizo relaçion diciendo que por el mes de octubre o noviembre que agora avia pasado, estando en todos los pueblos del dicho Campo de Montiel y les avian saqueado sus casas e abiertas e se las abian llevado con grande alboroto y escandalo e a ellos les habían hecho muchos malos tratamientos y en la villa de Membrilla e Solana y Villanueva de los Infantes avian muertos siete o ocho de ellos sin causa ni raçon alguna no avian podido ni habian pedir su justicia porque no podía salir a darnos noticia de ello ni tenían ningún remedio porque los alcaldes de los dichos lugares les hazian otras muchos malos tratos e demás de esto no podian ni osaban salir del dicho campo porque les apaleaban y diciéndoles moros perros" 25 .

Especialmente relevante es, en este sentido, la noticia anterior de los moriscos del Campo de Montiel; su grado de discriminación fue fuerte en los primeros años de asentamiento en tierras castellanas por el pueblo y autoridades municipales. Después de unos años de asentamiento fuera del Reino de Granada, los granadinos fueron rehaciéndose económicamente y creando su conciencia de grupo. Este es el caso, entre otros, de los moriscos de Pastrana, cuyos privilegios de 1594 no se produjeron al azar. Pues, sabemos que con anterioridad a ese año, ya se reunían de forma secreta. En 1582, se indicaba que todos ellos eran "muy ricos y bien tratados" que tenían su propio jefe, llamado Sebastián Suárez, quien había conspirado junto a otros moriscos granadinos repartidos por las ciudades de Castilla para provocar un levantamiento de los moriscos con la ayuda de las tropas francesas del príncipe de Bearn, pero su conspiración fue desarticulada en $1582^{26}$. También se reunían secretamente, según ha señalado Juan Blázquez en la población conquense de Cañaveruelas, con otros disidentes de Huete y Guadalajara ${ }^{27}$.

El poder contar con un representante propio fue una circunstancia que hizo que su voz fuera escuchada por las autoridades municipales, otro caso es, que fuera admitidas o respetadas sus continuas protestas.

Es un hecho que demuestra que se preocupaban por su conciencia de grupo y por crear su propia comunidad para defender sus intereses. En numerosas ocasiones aparecen noticias en las actas del concejo, donde se menciona una protesta o petición del "representante" de los naturales del reino de Granada. Pero sus quejas en el concejo apenas eran atendidas. El malestar

25. AGS, RGS, 1571, junio, 8. Oficio al Gobernador del Campo de Montiel.

26. Contreras, Jaime: «Bandolerismo y Fueros: El Pirineo a finales del siglo XVI», en El Bandolero y su imagen en el siglo de Oro, Universidad Autónoma de Madrid, 1989, pp. 55-78.

27. BLAZQUeZ Miguel, Juan: La Inquisición en Castilla-La Mancha, Madrid, 1986, p. 38. 
de la comunidad morisca quejándose de los tratos de que eran objeto por parte de autoridades municipales y clérigos, había sido muy habitual con anterioridad al levantamiento de las Alpujarras.

No les había ido mejor la suerte a los granadinos con anterioridad a ser expulsados del reino de Granada en 1570; en la lucha por la igualdad de condiciones y el cumplimiento de las capitulaciones promulgadas por los Reyes Católicos. Así, por ejemplo, entre 1555 y 1568, los naturales del reino de Granada declaran un gran número de discriminaciones al consejo Real de Castilla. Fue en el Memorial de 1526, presentado a Carlos V, donde los moriscos presentaron sus primeras quejas por los malos tratos que padecían ${ }^{28}$.

Es en estas quejas donde podemos ver la actuación cada vez más drástica de Felipe II con los moriscos granadinos. La historiografía hispana e hispanística se ha ocupado ampliamente desde el siglo XIX de la actuación que tuvo Felipe II hacia los moriscos -en especial, hay que decirlo, de los granadinos-. Así mismo, en los últimos años han vuelto a proliferar estos estudios con motivo del cuarto centenario de su muerte, que se celebrará en $1998^{29}$, así que hacer nuevas aportaciones es más que difícil.

Por nuestra parte nos centramos en la documentación procedente del Registro General de Sello, fondo documental escasamente manejado para el período de Felipe II por no encontrarse catalogado, a través de un estudio de las Provisiones Reales dadas por el monarca a los moriscos granadinos, y las múltiples quejas por el escaso respeto y comprensión que hubo hacia la comunidad morisca en el cumplimiento estricto de los acuerdos, capitulaciones y provisiones reales que se les iban imponiendo para conseguir una integración más rápida en la sociedad cristiana.

Observamos en la documentación del Sello como las quejas de los "naturales del Reino de Granada" se van incrementando desde la centuria de los años 50 del siglo XVI hasta provocar la rebelión de las Alpujarras. En esta sección del Archivo General de Simancas aparece una amplia tipología de demandas de los moriscos ante el Consejo Real de Castilla. Entre ellas, podemos destacar: el rechazo de Felipe II a renovar los Edictos de Gracia, no poder llevar armas, los altos servicios ordinarios y extraordinarios que tenían que pagar, la discriminación sufrida por parte de las autoridades reales y el no poder poseer esclavos negros.

Así pues, desde el comienzo del reinado de Felipe II hasta el levantamiento de las Alpujarras pasan más de diez años en que la intransigencia hacia el problema morisco se va incrementando y se abandona toda política de asimilación pacífica y meditada.

28. Aranda Doncel, A.: Moriscos en Tierras de Córdoba, Córdoba, 1987, p. 54.

29. Entre los numerosos estudios destacamos, BENITEZ SÁNCHEZ-BlANCO, R.: «Felipe II y los moriscos. El intento decisivo de asimilación, 1559-1568», en Estudios de Historia de Valencia, Valencia, 1978, pp. 183-201. 
Las capitulaciones otorgadas por los Reyes Católicos el 25 de noviembre de $1491^{30}$, darán lugar a una nueva relación entre la población granadina y sus nuevos gobernantes, pero las aparentes ventajas dadas a los musulmanes que permanecen en el reino de Granada, como eran el mantenimiento de su cultura y costumbres islámicas fueron en "apariencia". Puesto que a partir de la segunda mitad del siglo XVI, coincidiendo con la llegada al poder de Felipe II se irán reduciendo y provocarán el levantamiento morisco.

La historiografía del siglo XIX puso de manifiesto que las numerosas ventajas dadas por los monarcas a los musulmanes para conseguir una rendición más pronta del pueblo, eran imposible de mantener en un estado centralizado y cristiano. Manuel Danvila indica al hablar de las Capitulaciones, que fueron el "origen de desorden, una causa originaria de perturbación" siendo la causa originaria de ochenta años de enfrentamiento morisco-cristiano como causa de la intransigencia y poca habilidad de negociación de la monarquía ${ }^{31}$.

Los problemas exteriores de la Monarquía Hispánica habían distraído a Felipe II de la situación de los moriscos tanto valencianos como granadinos. Fue a partir de 1559, tras la finalización de los enfrentamientos con la monarquía francesa y la firma del Tratado de Chateau-Cambreis, movió a Felipe II a llevar a cabo una autentica evangelización de las comunidades moriscas peninsulares $^{32}$. Felipe II sabía que la integración de los moriscos en las condiciones que se encontraban en el reino de Granada era realmente difícil, se necesitaba tomar medidas prontas en el asunto. La conversión en apariencia asusta al rey. Para ello, intentó llevar a cabo su evangelización definitiva. La jerarquía eclesiástica y la Inquisición deseaban una conversión auténtica ${ }^{33}$. Designa a personajes de su confianza para ocupar las sedes arzobispales de Granada y Valencia, e incluso reúne concilios para debatir el problema. En el Sínodo de Granada de 1565 se produce un cambio radical en la política empleada contra los moriscos ${ }^{34}$.

Felipe II nunca estuvo a favor de los Edictos de Gracia concedidos a los moriscos. Aunque la Inquisición tenía en los moriscos una amplia fuente de

30. Sobre los textos y provisiones reales, véase: GARRIDO ATIENZA, M.: Las Capitulaciones para la entrega de Granada, Granada, 1910.

31. Danvila y COllado, M.: La Expulsión de los moriscos españoles, Madrid, 1889, p. 70.

32. Benítez SÁnchez-Blanco, R.: «Proyectos de aculturación en Valencia. De Tomás de Villanueva a Juan de Ribera», en Actes du II Symposium Internacionel du C.I.E.M., Túnez, 1984, p. 54.

33. Sobre la actuación de la Inquisición con los moriscos granadinos, véanse los siguientes trabajos: GARCía IVARS, Flora: La represión en el tribunal Inquisitorial de Granada. 1550-1819, Madrid, 1991; GARRAD, K.: «La inquisición y los moriscos Granadinos, 1526-1580», en Bulletin Hispanique, 1965, pp. 63-77.

34. Vincent, Bernard y Dominguez Ortiz, Antonio: op. cit., p. 32; Marín OCETE, A.: «El Concilio Provincial de Granada de 1565», en Archivo Teológico Granadino", 1962, 25, pp. 23-178. 
ingresos ${ }^{35}$. Este hecho lo comprobamos en 1559, cuando se quejaban los moriscos de Granada, diciendo:

"que en la solicitud de los negocios que prenden en el Consejo de la Santa Inquisición cerca del edito de gracia que por sus partes se piden de que a mas de dos años se trata, se han gastado setecientos y setenta y un mil y novecientos e noventa e cinco maravedíes, ansi en la solicitud y otorgar poderes, como en otros gastos y jornadas que sobre ello se han hecho a esta nuestra corte $y$ Flandes"36

Era un gran desembolso económico para conseguir una cierta tolerancia para mantener sus costumbres y tradiciones. Pero, pronto estas libertades y excesiva tolerancia no fueron del agrado del monarca y decidió reducir las libertades que recibían sus súbditos granadinos. Este nuevo giro en la política del monarca produjo a los moriscos múltiples gastos en la negociación del Edicto de Gracia, que no eran atendidos con prioridad por el monarca.

Otra molestia ocasionada a los moriscos fue la de no permitirles que llevaran armas. En el reino de Valencia por Orden Real se desarmó a los moriscos en enero de $1563^{37}$. Ese mismo año, en el mes de mayo, Felipe II dirigió al capitán General de Granada una cédula Real por la que obligaba a los moriscos a presentar todas sus armas y los que tuvieran licencia para usarlas a declararlas dentro de cincuenta días, bajo pena de galeras ${ }^{38}$. En el Reino de Granada ya se estaba debatiendo el tema de la posesión de las armas. En 1554, se había escrito al corregidor para que tomase medidas contra los moriscos que llevan armas en las Alpujarras sin licencia para ello ${ }^{39}$.

Eran controlados prácticamente en todas sus actividades económicas. Tenían también algunas trabas en su vida comercial. En 1560, se ordenaba por el Consejo de Castilla a las justicias locales:

"que las justicias de ella han començado a hazer molestias y vejaciones a sus partes so color de una pragmática que avia sido fecha en Madrid el año pasado de quinientos e cinquenta e dos que disponía que nyngun mercader extranjero, moriscos ni arriero por si ny por interposicion de persona pueda compra oro y plata en barra ni en plata sopena de la ver perdido y que sea desterrado perpetuamente de esos reino la que la pragmática manda siendo pregonada en esa dicha ciudad y reino..." ${ }^{\prime 40}$.

35. GARRARD, K.: «La Inquisición y los moriscos Granadinos», en Bulletin Hispanique, 1956, p. 67.

36. AGS, RGS, 7 de diciembre de 1559.

37. Salvador Esteban, Emilia: Felipe II y los Moriscos Valencianos. Las repercusiones de la Revuelta Granadina (1568-1570), Valladolid, 1987, p. 19.

38. MuÑoz y Gaviria, José: Historia del alzamiento de los moriscos. Su expulsión de España y sus consecuencias en todas las provincias del reino, Madrid, 1861, p. 112.

39. AGS, RGS, 1554, 30 de abril de 1554 .

40. AGS, RGS, 29 de marzo de 1560. 
Por otra parte, una forma de enriquecimiento rápido de los mercaderes moriscos se les había impedido, puesto que los negociantes con las Indias adquirían metales de oro y plata procedentes de América antes que fueran registrado en la Casa de Contratación de Sevilla.

Se sentirán discriminados por no haberse cumplido los privilegios que les habían sido otorgados por los monarcas. Pero los abusos hacia esta minoría se incrementan sustancialmente. Así, por ejemplo, fueron atropellados en el uso indiscriminado de animales de carga de su propiedad por parte de los cristianos. En 1558, se quejan los moriscos de Granada al consejo Real, con los siguientes términos:

“que algunos caballeros y otras personas que heran de dichas ciudades querían salir fuera de ella tomaban a los dichos cristianos nuevos sus partes y gente pobre sus bestias y las cargaban con tan gran carga como no les costaba ninguna cosa que se las mataban y se las impidian y es hortaban que no labrasen sus haziendas, y estaban aguardando a que salieren a sus labores por les tomar las azemillas y asi se las tomaban con grade alboroto y les dexaban las cargas que llevaban en los caminos y les hazian muchas molestias y bexaciones" ${ }^{\prime 4}$.

Las cargas fiscales que se les habían puesto eran importantes, sabemos que estaban obligados a pagar unos servicios extraordinarios a la corona; se les repartía un servicio anual, y en otras ocasiones servicios extraordinarios. En 1557, tenían que pagar 60.000 ducados para la obra de la Alhambra de Granada ${ }^{42}$. En 1558, se otorga poder al conde de Tendilla y al corregidor de Granada para cobrar veintiún mil ducados del repartimiento con que servían los moriscos anualmente, según este poder el servicio se hacía desde el año 1554, los fines eran:

41. AGS, RGS, 20 de julio de 1558.

42. AGS, RGS, 1557-IV-10. Poder para el conde de Tendilla y corregidor de Granada para el repartimiento del servicio de los LX mil ducados para la obra de la casa Real de Granada. "...sabeis como los cristianos nuevamente convertidos de esa çiudad y de las otras çiudades, villa y lugares de ese reyno que se juntaron en esa dicha çiudad al repartimiento de los veinte y un mil ducados del servicio ordinario por virutd de los poderes que les fueron concedidos por los nuevamente convertidos de ese dicho reino con la voluntad que siempre han tenido a nuestro servicio y teniendo consideración a los muchos gastos que se nos han ofrecido y cada día se nos ofreçen y a los que se han hecho y hazen en la obra de la casa real de la Alhambra y lo mucho que es menester para la acabar y por que aquello no cese pues de nuestras rentas reales, no se puede proveer lo necesario para ello por las causas que están dichas; $y$ visto que le servicio que se nos otorga para la dicha otra, el año pasado de mil y quinientos y cincuenta y uno, es ya cumplido, ovieron por bien, de nos otorgar, y servir de más del dicho servicio ordinario con otros sesenta mil ducados, los cincuenta mil ducados de ellos para la obra de la dicha casa y los diez mil ducados restante para hazer de ella lo que fuesemos servido pagar en seis años, que comiencen desde el primero día del enero de este presente año de mil y quinientos y cincuenta y siete en adelante, en cada uno de ellos diez mil ducados...". 
"para ayuda a los gastos que continuamente se hacen en las armadas contra los moros de allende e enemigos de nuestra Santa Fe Católica y pagar la gente que tenemos por tierra en la costa de la mar de ese dicho reino" 43 .

Las primeras medidas abusivas contra los moriscos granadinos fueron dadas en las Cortes de Toledo de 1565, en las que se prohíbe a los moriscos que se sirvan de esclavos negros: "porque los hacían moros" 44 . Fueron por este motivo las quejas más señaladas y reiterativas que aparecerán en el Registro General del Sello. Ya surgieron en $1562^{45}$, continúan años después no sólo con granadinos, sino con otros moriscos asentados en el Reino de Murcia $^{46}$ y en las Islas Canarias ${ }^{47}$.

Las medidas tomadas en las Cortes de Toledo fueron muy radicales contra los moriscos, pero las circunstancias del momento empujaron a Felipe II a realizarlas. En esos años el peligro turco era una gran amenaza para la monarquía hispánica y su conexión con los moriscos granadinos podría suponer graves problemas para el mantenimiento del territorio peninsular bajo el control cristiano; temía también la monarquía de los Austrias una posible conexión de los moriscos con los árabes y berberiscos del norte de Africa. En Europa en la década de los sesenta del siglo XVI se habían producido fuertes enfrentamientos religiosos como fue la guerra de Religión en Francia a partir de 1562 y la sublevación de los Países Bajos en 1566, lo que suponía para la monarquía española un posible levantamiento morisco en Granada con la ayuda exterior turca por el Mediterráneo. Como ha señalado Juan Reglá (1971) la presión turca hizo que Felipe II tuviera que adoptar una política intransigente con los moriscos ${ }^{48}$. En su pensamiento estaban presentes los duros enfrentamientos producidos en los Países Bajos y en Francia que podían desarticular totalmente a la monarquía que él encabezaba.

El peligro que suponían los moriscos del litoral mediterráneo por su conexión con turcos y berberiscos del norte de Africa parece ser que no existió como tal, y tampoco existió conexión interna entre los moriscos valencianos y

43. AGS, RGS, 1559-I-20.

44. Cabrera de Córdoba, L.: Felipe II. Rey de España, Madrid, 1876, Tomo I, Libro V, capítulo IV, pp. 279-280.

45. AGS, RGS, 28 de enero de 1562. Carta sobre lo de los esclavos negros que tienen los moriscos a pedimento de los naturales del reyno de Granada, se informa al corregidor de Granada "que en las Cortes que tuvimos e celebramos en la Cibdad de Toledo el año pasado de mil quinientos e sesenta a suplicación de todos los procuradores de este reino.. mandamos que ningún morisco de estos reinos pudiese tener esclavos negros so ciertas penas...".

46. AGS, RGS, 30 de enero de 1562 .

47. AGS, RGS, 24 de enero de 1562.

48. Reglà CAMPistol, J.: Estudios sobre los moriscos, Valencia, 1971, p. 144. 
granadinos con anterioridad al levantamiento de las Alpujarras ${ }^{49}$. La conexión que pudiera existir entre los moriscos granadinos y los valencianos ha sido estudiada por Emilia Salvador, indicando que apenas tuvo repercusión ${ }^{50}$.

A todos estos hechos, hay que unir la desconfianza del monarca hacia el marqués de Mondéjar y su política practicada con los moriscos. La pragmática de 17 de noviembre de 1566, no es del gusto de Mondéjar. Las leyes ordenadas por Felipe II en 1566 no son consultadas al capitán General de Granada, personaje que practicaba una política de tolerancia y conciliación con los moriscos, que no era del agrado del monarca ${ }^{51}$. Desde entonces su amistad con la familia Mendoza de Granada se distancia y se acabará definitivamente al ser sustituido Mondéjar de su puesto de capitán General y nombrado en su lugar don Juan de Austria, por provisión Real promulgada el 30 de marzo de $1569^{52}$. El tercer marqués de Mondéjar, don Iñigo López de Mendoza (1511-1580) era un personaje muy endeble y había tenido con anterioridad fuertes enfrentamientos con el presidente de la Audiencia de Granada, Deza, lo que hizo que Mondéjar tuviese que venir a la Corte ${ }^{53}$.

La Real pragmática de 17 de noviembre de 1566, que fuera pregonada en Granada el 1 de enero de 1567, priva a los moriscos de sus tradiciones y costumbres como eran: el no poder emplear su lengua y escritura árabe, no se permite ni escribir ni hablar en árabe, ni vestir a la morisca. Tampoco podían usar las marlotas, calzas y llevar la cara tapada las mujeres. También se les volvía a indicar que no podían tener esclavos negros, ni gacis, ni celebrar

49. GARCÍA CÁRCEL, R.: «Granada para los moriscos valencianos: ¿mito abstracto o modelo operativo?», en Actas del I Congreso de Historia de Andalucia, Tomo I, pp. 397-400. Pone de manifiesto que no hubo relación alguna entre la comunidad de Valencia con la de Granada antes de 1568.

50. SALVADOR ESTEBAN, Emilia: Felipe II y los moriscos valencianos. Las repercusiones de la Revuelta Granadina (1568-1570), Colección "Síntesis", VI, Universidad de Valladolid, 1987.

51. SPIVAROVSKY, Erika: «Un episodio del Gobierno de la Alhambra por el quinto conde de Tendilla (1569)», en Hispania, 118, 1971, p. 399.

52. AGS, RGS, 1569-III-30. Para que el señor don Juan de Austria vaya a la ciudad de Granada y tenga a su cargo todo lo de aquel Reino: "Don Felipe, ecetera... Entendiendo por lo que el marqués de Mondéjar, nuestro capitán General del Reino de Granada nos ha escripto el estado en que esta al presente se hallan y están las cosas del y teniendol deseo que es razón de poner en ellas la orden que más convenga al servicio de nuestro señor y mio, bien del dicho reino y importando lo que importa quesieramos mucho poder yr en persona para que con nuestra presencia se pudiera hazer con más brevedad y presteza, pero ofreciendose otras cosas de memos importancia a que forzosamente yo he de atender y asistir sin poder lo escusar y que por esta causa conviene enviar al dicho reino de Granada persona de mucha autoridad, confiando que vos el ilustrisimo don Juan de Austria mi muy caro y muy amado hermano entendereis en lo suso dicho como conviene y es necesario...".

53. Caro Baroja, Julio: Los moriscos del Reino de Granada, Madrid, 1985, p. 152. Según datos procedentes de IbÁNEzZ de SeGovia, Gaspar, Historia de la Casa de Mondéjar, libro VI, cap. X, fols. $449 \mathrm{r}-499 \mathrm{v}$. 
bodas y festividades a la morisca, ni emplear cantares moriscos como las zambas y leilas, y no poder usar los baños ${ }^{54}$.

La discriminación por parte de la justicia local y real fue una constante, protestan los moriscos contra los abusos de las autoridades reales, atacando a los alcaldes mayores y corregidor de Granada que son los encargados de ejecutar las ordenes reales. Entre los oficiales que aplicaban la justicia y los moriscos hubo enfrentamientos y acusaciones mutuas entre ambas partes. En 1561, los nuevamente convertidos del Reino de Granada, acusaban al corregidor de Granada, don Hernando Carrillo de Mendoza, entre otras cosas, de tener alguaciles naturales de la ciudad y vecinos de ella ${ }^{55}$.

En 1566, manifestaban al Consejo Real:

"rescibian grandes molestias y bexaciones de los alguaciles y ministros de justicia de la dichas cibdades.. porque entraban en sus casas por fuerza e contra su boluntad les tomaban las gallinas que querían y no les pagaban por ellas sino medio real o veinte maravedíes por cada una valiere a tres y cuatro reales" ${ }^{\prime \prime 6}$.

El hecho, según lo que vemos aquí, parece claro: a los moriscos después de medio siglo de la conquista de Granada la monarquía va reduciendo sus libertades, sobre todo, para conseguir una verdadera integración social y religiosa ${ }^{57}$.

Los moriscos manifestaron sus quejas abiertamente al Consejo Real, pero no fueron escuchados ni admitidas; en una situación desesperada se vieron empujados como única salida a la rebelión y al reconocimiento de los derechos que poseían antes de 1492. Cabrera de Córdoba resume su actuación con estas palabras:

"Viendo los moriscos que no eran admitidas las suplicas para suspender las premagticas, y que la ejecución les molestaba... y trataron sobre el tomar las armas para su libertad y venganza de los cristianos..." ${ }^{28}$.

Entre 1570 y 1610, los moriscos habían permanecido al margen de la sociedad sin intregarse, ahora se decide expulsarlos.

54. CARO BAROJA, Julio: op. cit., p. 172. Existe una pragmática relativa a este asunto en AGS, RGS, 1567-IV, 17 de noviembre de 1566: Para que aqui adelante los moriscos del Reino de Granada en las bodas, desposorios, belaciones e fiestas que hizieren no usen de ritos ni ceremonias moriscas e guarden la Santa Madre Iglesia.

55. AGS, RGS, 1561-II, 30 de enero de 1561 .

56. AGS, RGS, 21 de febrero de 1565.

57. GutIÉRREZ NiETo, J. I.: «La discriminación de los conversos y la tibetización de Castilla por Felipe II», en Homenaje a Gómez Moreno, Revista Universidad Complutense, Vol. 87, julio - septiembre 1975, pp. 99-103.

58. CABRera de Córdoba, L.: op., cit., p. 595. 


\section{CONCLUSIÓN}

Hemos visto cómo los moriscos de Pastrana mantuvieron su estructura de grupo, tradiciones islámicas y mentalidad propia de su origen musulmán. Lucharon con fuerza contra la hostilidad del entorno. La situación de marginación continuó siendo similar durante el reinado de Felipe II a como lo era en el Reino de Granada con anterioridad al levantamiento de 1568. Felipe II nunca tuvo el trato favorable que hacia los moriscos había tenido Carlos V.

La comunidad morisca de Pastrana es, ante todo, una clase marginada que poco a poco, con el apoyo de los duques, consigue una mayor consideración social e importancia económica, lo que hará que consiga mayor libertad de movimiento y consideración ante la justicia.

Los nuevos pobladores de Pastrana que habían sido derrotados de Granada fueron tomando conciencia de grupo ante la creciente marginación que sufrían, y la abusiva política fiscal que les fue impuesta. La marginación fue una constante a lo largo de los cuarenta años de estancia en esta localidad. A pesar de la organización que existió dentro de la esta comunidad disidente de Pastrana, siempre fue totalmente marginada de las decisiones del concejo.

La comunidad morisca originaria del Reino de Granada al ser trasladada al centro peninsular se encontró con un entorno similar al que tenía en Granada, ambos lugares tuvieron un comportamiento similar ante la discriminación de la justicia, que fue su lucha para ser reconocidos sus derechos. 